\title{
Evaluation of the Effect of Rubber Modified Bitumen on Asphalt Performance
}

\author{
Biruk Yigezu Tefera ${ }^{1}$, Kassa Tadele ${ }^{2}$, Anteneh Geremew ${ }^{1}$ \\ ${ }^{1}$ Faculty of Civil and Environmental Engineering, Jimma University, Institute of Technology, Jimma, Ethiopia \\ ${ }^{2}$ Ethiopian Construction Design \& Supervision Works Corporation, Addis Ababa, Ethiopia
}

Email address:

birukobama@gmail.com (B. Y. Tefera), kassatad@yahoo.com (K. Tadele), antjiren@gmail.com (A. Geremew)

To cite this article:

Biruk Yigezu Tefera, Kassa Tadele, Anteneh Geremew. Evaluation of the Effect of Rubber Modified Bitumen on Asphalt Performance. American Journal of Civil Engineering. Vol. 6, No. 3, 2018, pp. 87-92. doi: 10.11648/j.ajce.20180603.11

Received: May 3, 2018; Accepted: May 28, 2018; Published: June 15, 2018

\begin{abstract}
For over a century, paved roadways have been constructed using asphalt concrete mixes across the world. This research was aimed on evaluation of the effect of the waste rubber tire modified bitumen on Asphalt performance, to investigate physical properties such as the stability and flow. Marshall Stability Method was used to determine the Optimum Binder Content $(\mathrm{OBC})$ and to evaluate the properties of the crumb rubber. Five different percentage of rubber by weight of bitumen: $0 \%, 5 \%, 10 \%, 15 \%, 20 \%$ were used. A comparative study is made among the unmodified and modified bitumen samples using the various sizes of waste rubber tire bitumen particles and the modified. The results of the study revealed that as rubber content increase from 0 to $20 \%$ penetration decreased from 68.5 to $58.5 \mathrm{~mm}$. Similarly, for the same percentage increase in rubber content ductility decrease from 100 to $75 \mathrm{~cm}$. Asphalt mixes with crumb rubber $15 \%$ have higher stability, it is two times more than the minimum specification and lower marshal flow. From this study it is concluded that recycled crumb rubber can therefore be beneficial to the performance of the asphalt concrete pavements as well as provide a means of safe disposal of these non-biodegradable wastes.
\end{abstract}

Keywords: Crumb Rubber, Fatigue Cracking, Marshal Stability Method, Optimum Binder Content, Recycled Crumb Rubber

\section{Introduction}

The depletion of natural resources and the increase of solid wastes have become a major concern throughout the world. With the call for the use of sustainable and eco-friendly construction materials, officials, governmental agencies, and researchers are evaluating the use of alternative materials (i.e., recycled materials) in construction projects. [1] With the increase of asphalt pavement materials costs, alternative cheap materials are being utilized in the designs of asphalt pavements and more attention is focused on the use of recycled materials in the pavement industry. [2].

The global problem with landfill disposal of automobile tires can only be solved by the feasible option left, and that is recycling and utilization of the recycled products. It is thought that the application of recycled automobile tires will not only solve the environmental of these industrial solid wastes problem but also act as very promising modifiers for the improvement of asphalt pavement material. [2] The use of crumb rubber in asphalt pavements has shown promising results in previous studies (Shafabakhsh et al. 2014; Hossain et al. 2016; Ghavibazoo, Abdelrahman 2014). [3-5]

Modified bitumen using crumb rubber showed an improvement in the performance of pavements over the base binders as a result of the interaction of crumb rubber with base binders. Crumb rubber is a general term used to describe a granular rubber from waste tires that is reduced in size for use as modifier in asphalt paving materials. The properties of the crumb rubber that can affect the interaction include production process, particle size, specific surface area, and chemical composition. Due to this interaction, there are noticeable changes in the viscosity, physical and rheological properties of the rubberized 
bitumen leading to high resistance of rutting of pavements. Crumb Rubber Modifier (CRM) because its use modifies the properties of the resultant hot mix asphalt concrete product. [6-8]

The main purpose of this research is to evaluate the performance of rubber asphalt modifiers, representing some of the major types of modifiers, to determine which provided the best, most cost-effective performance improvement. Conventional way of road construction have been experiencing problem of premature failure of pavements like potholes, roughness, cracks and etc. which leads to poor performance of roads and its life. On the other hand, rubber modified bitumen have an advantage of higher resistance to deformation at elevated pavement temperature, better age resistance properties, higher fatigue life of mixes, better adhesion between aggregates and binder, prevention of cracking and overall improved performance in extreme climatic conditions and under heavy traffic conditions. The best results were found in a mix containing $15 \%$ rubber content.

\section{Methodology}

This study involved investigating the Marshal properties of bituminous mixtures prepared in the laboratory using different amount rate of crumb rubber ranging from $0-20 \%$. The effectiveness of crumb rubber modified bitumen were evaluated by comparing test conducted on unmodified (virgin) specimens. All tests on aggregate, asphalt binder, loose mixtures, and compacted specimens were conducted according to respective AASHTO and ASTM testing standards.

These ingredient materials were subjected to various laboratory tests in order to determine their physical properties whether they can meet common specification limits. These quality assurance tests conducted on the aggregates include: gradation, Los Angeles abrasion, soundness, flakiness, aggregate crushing value and specific gravity. The tests carried out on the asphalt cement sample include: penetration, flash point, ductility, durability and specific gravity.

Evaluating the properties of used materials as bitumen, aggregates, and crumb waste tire and carrying out sieve analysis for crumb waste rubber and each aggregate type, blending of aggregate was carried out to obtain the binder average gradation curve which used in the preparation of the asphalt mix.

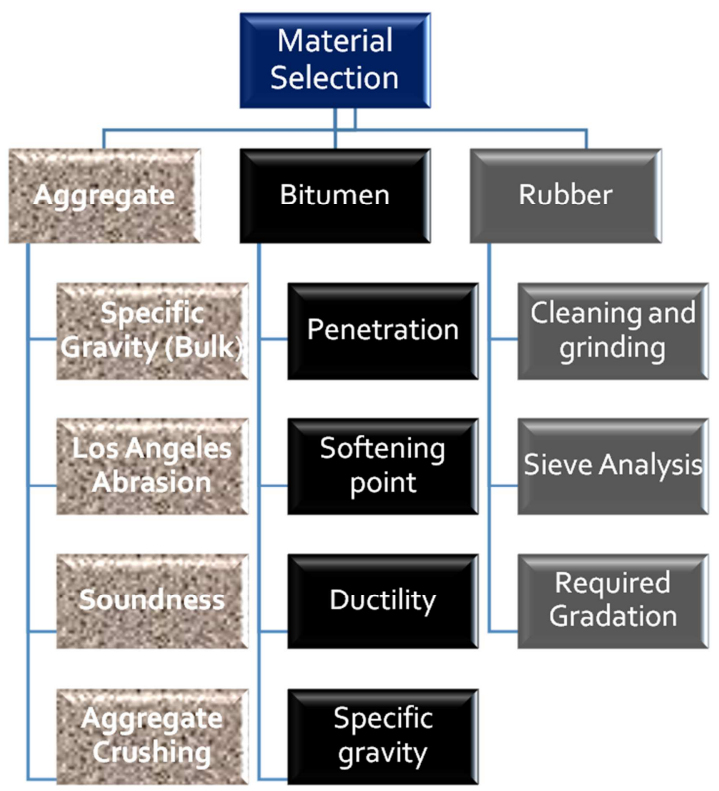

Figure 1. Material and quality tests used for marshal mix design.

After that, with different bitumen and crumb rubber contents asphalt mixes are prepared to obtain optimum bitumen content by Marshall Test. Then optimum binder content with their respective ratio is used to prepare asphalt mixes. Marshall Test was used to evaluate the properties of these rubber modified bitumen mixes. Finally, laboratory tests results are obtained and analyzed.

\section{Result and Discussion}

\subsection{Effect of Rubber on Penetration}

This test is very vital to empirical measurement of consistency of bitumen. The test, is a measure of hardness, it was performed by allowing a needle of specified dimensions, which is loaded to $100 \mathrm{~g}$ to penetrate into the material for a period of 5 seconds. Penetration was measured by the distance the needle sinks into the bitumen, in units of $1 / 100 \mathrm{~cm}$

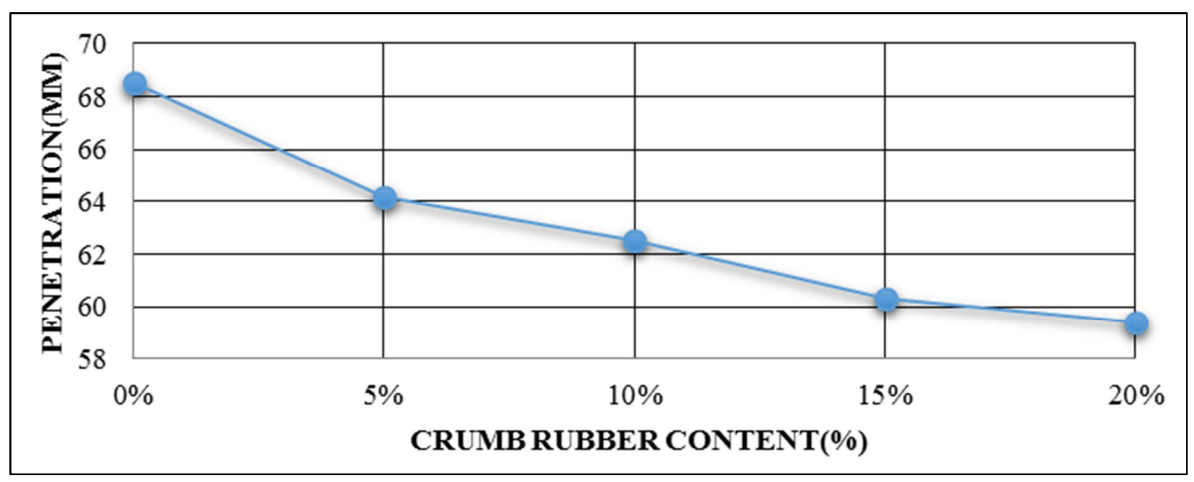

Figure 2. Penetration test with different amount of crumb rubber contents. 
The higher the penetration, the softer the bitumen. Bitumen with penetration grade of $60-70$ or $60 / 70$ means that the penetration of the needle in bitumen is in the range of 60 to 70 at standard test condition. As crumb rubber percentage increase from 0 to $20 \%$, penetration decreases from 68.5 to $59.5 \mathrm{~mm}$.

\subsection{Effect of Rubber on Softening Point}

This is a measure of temperature susceptibility and a measure of flow of bitumen in service. The test was performed in accordance with ASTM D36. It is a form of consistency test that determines the melting point of bitumen and is used for control in refining operation. The test for determining softening point is called Ball-and-ring / Softening point test. In the test, asphalt is placed in a small ring and chilled. The ring was then immersed in water or glycerin; a small steel ball was placed on the asphalt and heat was applied to the liquid. As the temperature was raised, the temperature at which the bitumen softens and the ball sinks to the bottom of container was the temperature corresponding to softening point.

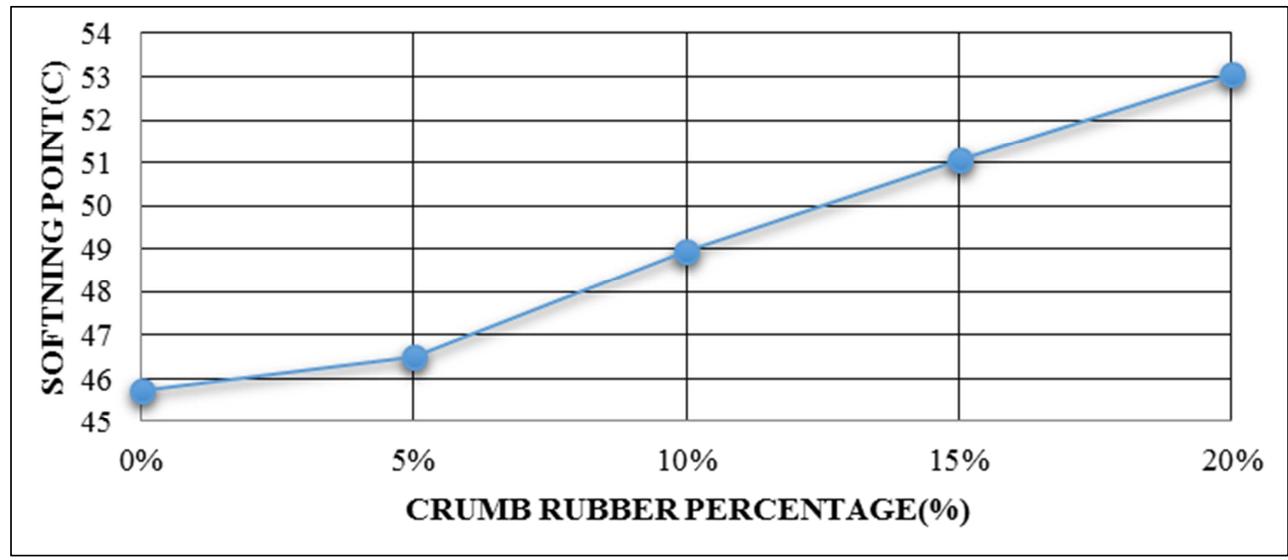

Figure 3. Softening point test with different amount of crumb rubber contents.

As percentage of rubber increase softening point increase due to the fact that addition of rubber increase resistance to temperature susceptibility and a measure of flow of bitumen.

\subsection{Effect of Rubber on Ductility}

Tensile behavior of bituminous binder or homogeneity of binder. Ductility of the rubber modified bitumen with various concentration shows lower value compare to conventional.

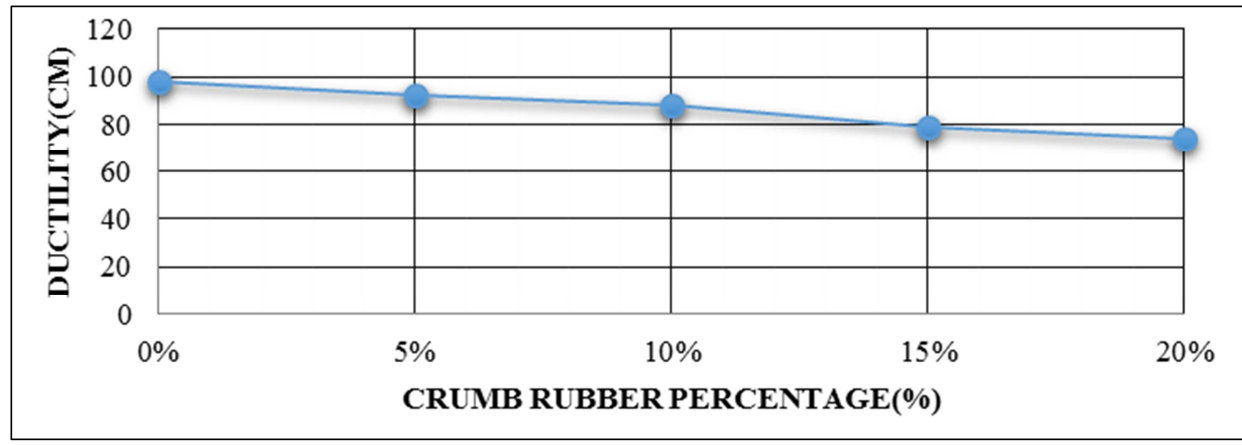

Figure 4. Ductility test with different amount of crumb rubber contents.

\subsection{Effect of Rubber on Marshal Stability}

It is noticed that all values of marshal stability for different rubber content satisfy the local specification and the maximum stability corresponds to $0 \%$ rubber content. As shown in Figure rubber modified bitumen rates have the stability value greater than the conventional rubber content.

The stability of the specimen is the maximum load required to produce failure of the specimen when load is applied at constant rate. 


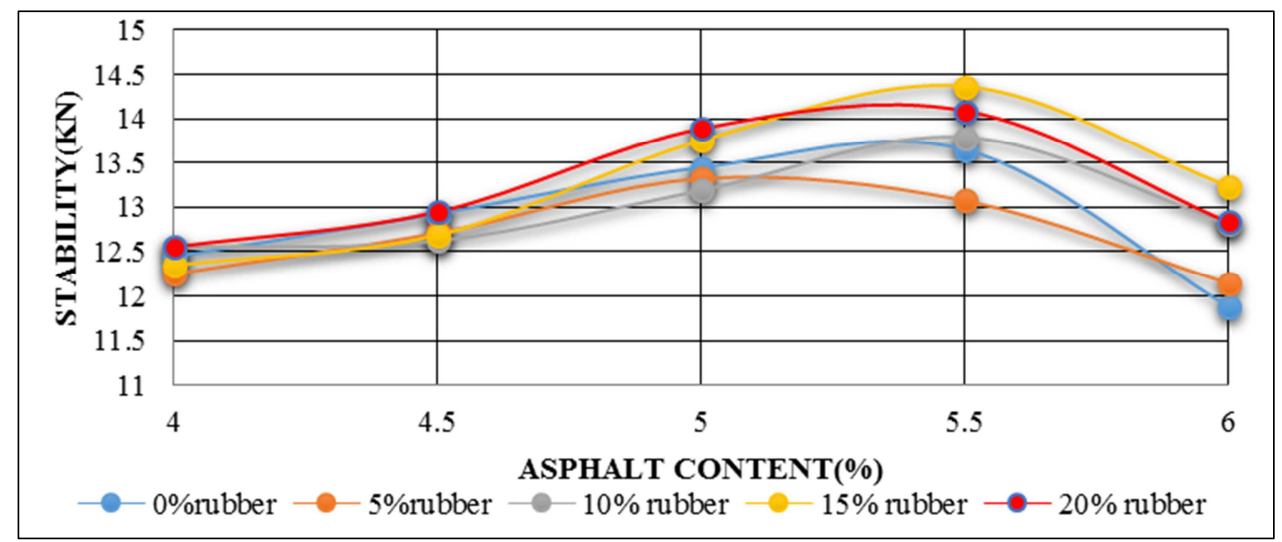

Figure 5. Effect of rubber content on Stability at various Asphalt content.

The figure can illustrate the above theory where small addition of rubber could decrease the stability of the mixture, also higher replacement could increase the stability by acting like asphalt extender. This is why mixture prepared using rubber content of $15 \%$ and $20 \%$ have high stability. The stability of the mixture with $5 \%$ rubber shows value below the control asphalt content.

\subsection{Effect of Rubber on Flow}

Flow refers the vertical deformation of the sample (measured from the start of loading to the point at which stability begins to decrease in $0.25 \mathrm{~mm}$. High flow value indicate a plastic mix that will experience deformation under traffic may indicate a mix with higher than permanent deformation under traffic, whereas low flow values may indicate a mix with higher than normal void and insufficient asphalt for durability and one that experience premature cracking due to mixture brittleness during life of pavement.

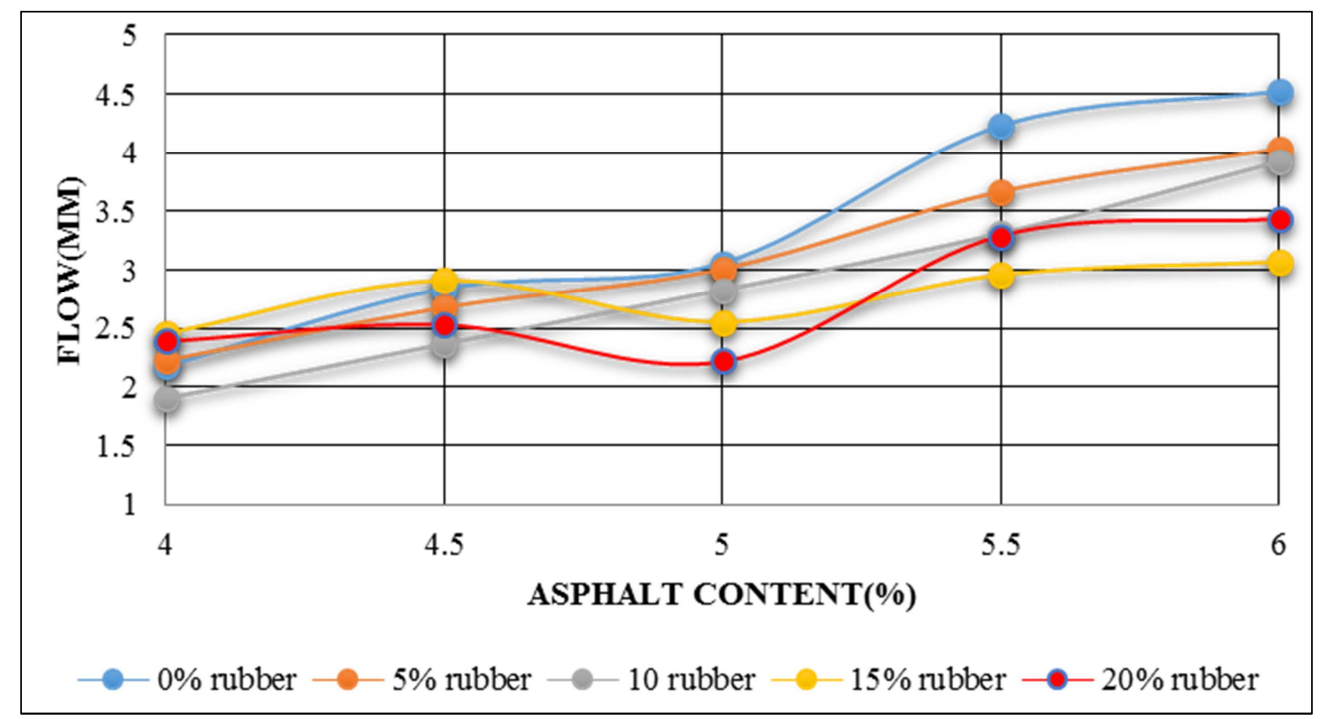

Figure 6. Effect of rubber content on Flow at Various Asphalt content.

The flow of rubber asphalt mixes is above $2 \mathrm{~mm}$ and still in the range of local and international specification at all different rubber content. Figure (4-3) shows flow results of rubber asphalt at different rubber content. For all rubber content the flow increase as the asphalt content increase. Similarly flow number shows in increment as the rubber replacement rate increase. The increased flow number out of the required specification range exposed the HMA for permanent deformation during their time of service.

\subsection{Effect of Rubber on Voids in Mineral Aggregate (VMA)}

The effect of different binders on voids in mineral aggregate was also evaluated and the result are shown in Figure 4-8. It is common trend that, as glass content in the mixes increase, the void in mineral aggregate increase. 


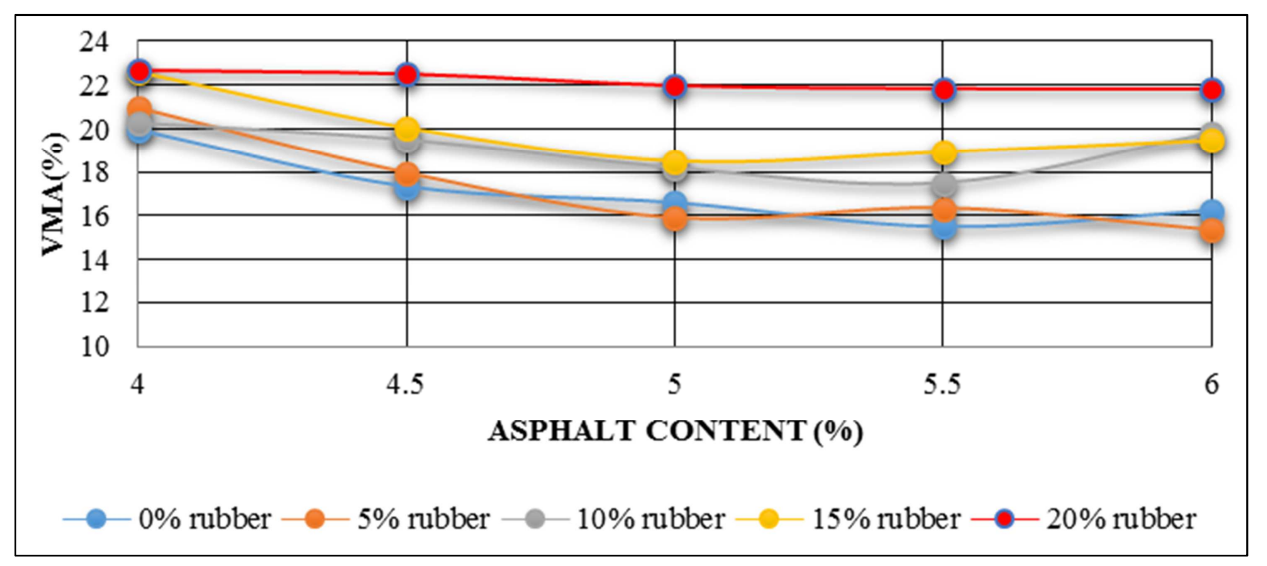

Figure 7. Effect of rubber content on VMA at various Asphalt content.

Minimum VMA is necessary in mixture to accommodate enough asphalt content, so that aggregate particles can be coated with adequate asphalt film thickness. This consequently results in a durable asphalt paving mixtures. It can be seen from the figure that lower VMA is in mixtures with no rubber and hence, results lower effective asphalt content (see figure 45). These mixes could be less durable than that of containing high rubber content. Higher voids in mineral aggregate are obtained from mixes prepared by $15 \%$ and $20 \%$ rubber replacement, results higher effective asphalt content.

\subsection{Effect of Rubber on Void Filled with Asphalt (VFA)}

Effect of rubber content on the voids filled with asphalt property of the mixture is indicated on Figure 4-9. Voids filled with asphalt values are greater than $60 \%$ for all rubber content, where the Marshal criteria for VFA is $65 \%-75 \%$. This criterion is important for the durability of mixes and is related to the effective asphalt content in the mix. If the percentage of void filled with asphalt is lower than the limit indicated, there will be less asphalt film around the aggregate particles. Lower asphalt films are more subjected to moisture and weather effects where they can be detached from the aggregate particles and subsequently lower performance. On the other hand, if the limit is exceeded, voids are filled with asphalt than required for durability.

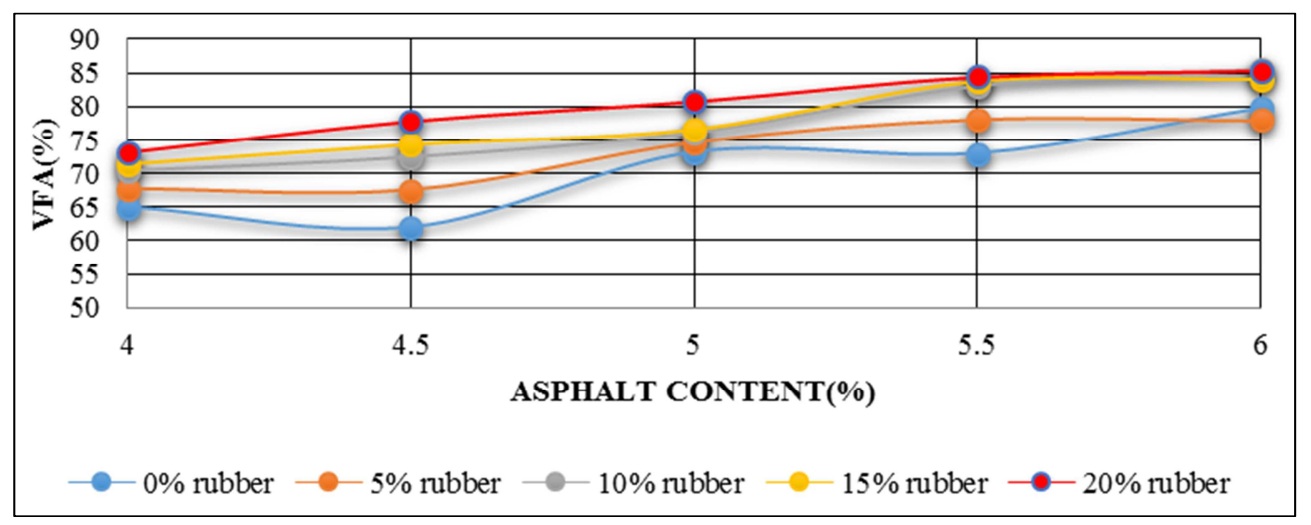

Figure 8. Effect of rubber on VFA various Asphalt content.

This can be explained as the asphalt film around aggregate particles is thicker and lower voids than required are left. This increased amount of effective asphalt results bleeding and lower stiffness of the mix.

Since VFA depends on both VMA and Va, the cumulative effect of these two variables are shown on Figure 4-9. For mixtures prepared by $15 \%$ and $20 \%$ rubber content shows relatively higher voids filled with asphalt compared with other mixes almost in all asphalt content.

\subsection{Summary of Results}

Table 1. Comparison of rubber modified bitumen asphalt mix with maximum rubber content and Ethiopian Road Authority Specification (ERA manual-2002) and international Specification.

\begin{tabular}{|c|c|c|c|c|c|c|c|}
\hline \multirow{3}{*}{ Marshal Method Mix Criteria } & \multirow{3}{*}{$\begin{array}{l}\text { Rubber } \\
\text { Content } \\
(15 \%)\end{array}$} & \multirow{2}{*}{\multicolumn{2}{|c|}{$\begin{array}{l}\text { Light Traffic } \\
\text { Surface - Base }\end{array}$}} & \multirow{2}{*}{\multicolumn{2}{|c|}{$\begin{array}{l}\text { Medium Traffic } \\
\text { Surface - Base } \\
\end{array}$}} & \multirow{2}{*}{\multicolumn{2}{|c|}{$\begin{array}{l}\text { Heavy Traffic } \\
\text { Surface - Base }\end{array}$}} \\
\hline & & & & & & & \\
\hline & & Min & Max & Min & Max & Min & Max \\
\hline Stability $\left(\mathrm{KN}\right.$ at $\left.60^{\circ} \mathrm{C}\right)$ & 14.36 & 3.5 & - & 6 & - & 7 & - \\
\hline Flow, (mm) & 3.07 & 2 & - & 2 & - & 2 & - \\
\hline
\end{tabular}




\begin{tabular}{|c|c|c|c|c|c|c|c|}
\hline \multirow{2}{*}{ Marshal Method Mix Criteria } & \multirow{2}{*}{$\begin{array}{l}\text { Rubber } \\
\text { Content } \\
(15 \%)\end{array}$} & \multicolumn{2}{|c|}{$\begin{array}{l}\text { Light Traffic } \\
\text { Surface - Base }\end{array}$} & \multicolumn{2}{|c|}{$\begin{array}{l}\text { Medium Traffic } \\
\text { Surface - Base } \\
\end{array}$} & \multicolumn{2}{|c|}{$\begin{array}{l}\text { Heavy Traffic } \\
\text { Surface - Base }\end{array}$} \\
\hline & & $\begin{array}{ll}\text { Surre } \\
\text { Min }\end{array}$ & Max & Min & Maxe & Min & Max \\
\hline Percent Air Voids & 3.56 & 3 & 5 & 3 & 5 & 3 & 5 \\
\hline Percent Voids filled with Asphalt (VFA) & 83.93 & 70 & 80 & 65 & 78 & 65 & 75 \\
\hline Percent VMA (for $4 \%$ air voids and Nom. Max, Particle size of $19 \mathrm{~mm}$ ) & 22.59 & 13 & - & 13 & - & 13 & - \\
\hline
\end{tabular}

\section{Conclusion}

Penetration and ductility decrease as percentage of rubber increase. The rubber percentage decreased the penetration, which would enhance rubber binder stiffness, and asphalt binder consistency and resistance to flow, which led to improve rutting resistance. Rubber-modified bitumen typically is more viscous (thicker) than unmodified binders, and tend to show improved adhesive bonding to aggregate particles. Rubber reduces the ductility of the bitumen and this will reduce creep and fatigue in bitumen material. The use of rubber tends to reduce the Void in Mineral Aggregate (VMA) and Air Void $\left(\mathrm{V}_{\mathrm{a}}\right)$ and increase Void Filled with Asphalt VFA from Marshall compacted specimens; thus, the optimum asphalt content must be determined with the target percent of rubber to be used. The bulk density increases with the addition of modifier in asphalt concrete mix. Higher marshal stability values were obtained from mixtures with amount rubber content increase all values above local and international specification. Problem like thermal cracking and permanent deformation are reduce in hot temperature region. The use of recycled crumb rubber can therefore be beneficial to the performance of the asphalt concrete pavements as well as provide a means of safe disposal of these non-biodegradable wastes. The process is eco-friendly.

\section{References}

[1] Angelone S, Cauhape' Casaux M, Martinez FO. 2016. Green Pavements: Reuse of Plastic Waste in Asphalt Mixtures. Mater Struct; 49 (5):1655-1665.0.
[2] Abu Abdo AM. 2016. Utilizing Reclaimed Asphalt Pavement (RAP) Materials in New Pavements - A Review. Int J Ther Env Eng; 12 (1):61-66.

[3] Shafabakhsh, G. H.; Sadeghnejad, M.; Sajed, Y. 2014. Case studies in construction materials case study of rutting performance of HMA modified with waste rubber powder, Case Studies in Construction Materials 1: 69-76.

[4] Hossain, Z.; Bairgi, B.; Zaman, M.; O’Rear, E. 2016. Viability assessment of the use of ground tire rubber asa modifier in asphalt binders, in Proc. of 95th Transportation Research Board Annual Meeting, 10-14 January 2016, Washington, D. C. http://dx.doi.org/10.1016/j.cscm.2014.04.005.

[5] Ghavibazoo, A.; Abdelrahman, M.; Ragab, M. 2013. Effect of CRM dissolution on storage stability of CRM modified asphalt, in Proc. of 92th Transportation Research Board Annual Meeting 6 (13): 1-14. http://dx.doi.org/10.3141/237014.

[6] T. U. Ganiron Jr., 2014. "Effects of human hair additives in compressive strength of asphalt cement mixture", International Journal of Advanced Science and Technology, vol. 67 , pp. 11-22.

[7] Al-Khateeb, Ghazi G., and Khaled Z. Ramadan. 2015. "Investigation of the effect of rubber on rheological properties of asphalt binders using superpave DSR."KSCE Journal of Civil Engineering 19, no. 1: 127-135.

[8] Zhang, Dong, Xiaoming Huang, Yongli Zhao, and Sulong Zhang. 2014 "Rubberized asphalt mixture design using a theoretical model." Construction and Building Materials 67: 265-269.

[9] ASTM (American Society for Testing and Materials), 2000.

[10] AASHTO (American Association State Highway and Transportation officials), 2009. 